Review began 01/22/2022 Review ended 01/31/2022 Published 02/02/2022

(c) Copyright 2022

Booth et al. This is an open access article distributed under the terms of the Creative Commons Attribution License CC-BY 4.0. which permits unrestricted use, distribution, and reproduction in any medium, provided the original author and source are credited.

\section{Tenosynovial Giant Cell Tumor After ACL Reconstruction With Autograft}

\author{
Michael Booth ${ }^{1}$, Edward B. McDonough ${ }^{2}$ \\ Morgantown, USA \\ Corresponding author: Michael Booth, michaelbooth997@gmail.com
}

1. Orthopaedics, West Virginia University, Morgantown, USA 2. Orthopaedic Surgery, West Virginia University,

\begin{abstract}
A 25-year-old male developed left knee pain several years after anterior cruciate ligament (ACL) reconstruction. MRI showed a suspected cyclops lesion over the anterior portion of the knee. The patient underwent diagnostic knee arthroscopy with lesion removal, and it was discovered the patient had a tenosynovial giant cell tumor. A tenosynovial giant cell tumor is a rare intraarticular lesion that requires a high suspicion for clinical diagnosis. Management is currently centered around arthroscopic versus open removal of the lesion with serial monitoring and advanced imaging for recurrence.
\end{abstract}

Categories: Oncology, Orthopedics, Trauma

Keywords: tenosynovial giant cell, acl, sports, trauma, orthopaedics trauma

\section{Introduction}

Synovial giant cell tumor most frequently occurs on the hand and uncommonly on the ankle or knee [1]. Tenosynovial giant cell tumor (TSGCT) is a family of lesions involving the joint synovia, bursae, and tendon sheath [2]. TSGCT is considered rare and has an incidence of 43 cases per million population per year and typically affects young patients in the third and fourth decades [3]. Localized TSGCT grows slowly over time and patients tend to present with pain and effusion in the joint and sometimes mechanical symptoms such as catching and locking [3]. There have been several case reports citing intraarticular knee TSGCT but there have been no previous reports of a TSGCT after anterior cruciate ligament (ACL) reconstruction.

\section{Case Presentation}

A 25-year-old male presented to our office complaining of intermittent left knee pain and swelling after undergoing a left knee ACL reconstruction with hamstring autograft six years ago. He injured his knee while performing a field goal in a collegiate football game and heard a "pop" with subsequent knee-buckling and swelling. The patient had an unremarkable postoperative course after his surgery and was very satisfied with his knee up until about the last month prior to presentation. The patient does not have any medical problems, has no family history of cancer, is not taking any medications, and enjoys jogging and playing basketball.

On physical exam, the patient had a left knee effusion when compared to his contralateral side, the range of motion of his left knee was from 0-120 degrees, with negative Lachman test and negative anterior/posterior drawer, and his knee was stable at 0 and 30 degrees of flexion to varus and valgus stress. The patient had an MRI performed in the emergency department several days prior, which showed a $17 \mathrm{~mm} \times 26 \mathrm{~mm} \times 16 \mathrm{~mm}$ lesion in the anterior portion of the left knee near the infrapatellar fat pad, which was read as a cyclops lesion (Figure 1). Given his mechanical symptoms and the large size of the lesion, the patient underwent a left knee diagnostic arthroscopy with foreign body removal. 


\section{Cureus}

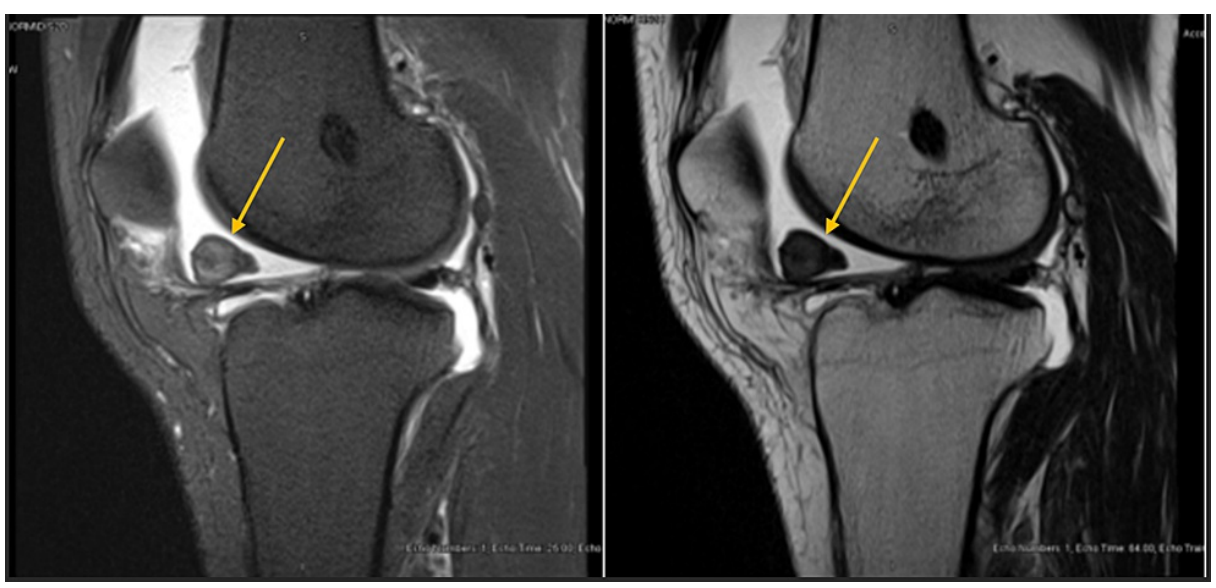

FIGURE 1: T2 (left) and T1 (right) MRI sagittal images of the left knee showing a heterogeneous foreign lesion over the anterior portion of the knee

Intraoperatively, there was no evidence of ACL tear or fraying, and the medial and lateral menisci were intact. The infrapatellar fat pad was noted to be hypertrophied and there was a large friable loose body with a stalk off of the previous ACL graft located within the notch (Figure 2), which was removed with a grasper and sent for pathology. The final pathology the next day revealed a localized type tenosynovial giant cell tumor (Figure 3). After consulting with our orthopedic oncology team, our plan is to monitor the left knee for recurrence with MRI at six months and again in two years' time.

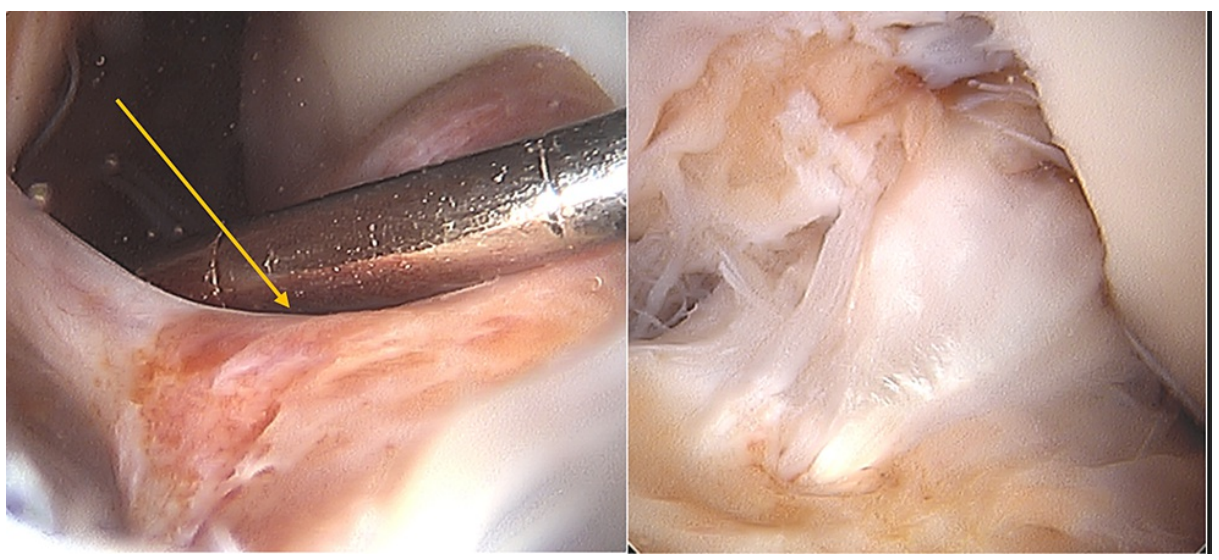

FIGURE 2: Intraoperative images of the knee showing the tenosynovial giant cell tumor before (left) and after (right) debridement, which revealed the $A C L$

$\mathrm{ACL}$ : anterior cruciate ligament 


\section{Cureus}

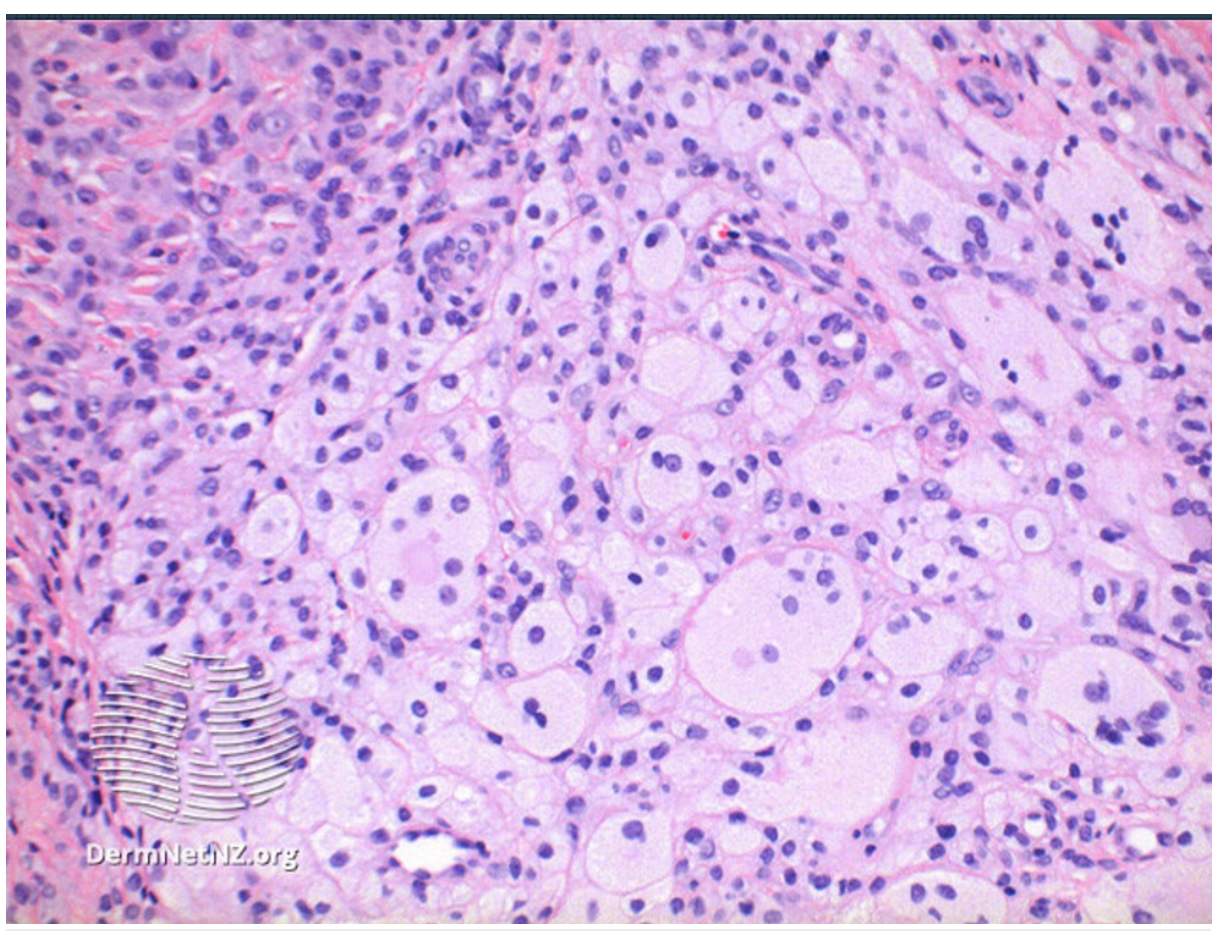

FIGURE 3: Giant cell tumor of tendon sheath pathology

Image used in accordance with DermNet NZ image use policy. Link: https://dermnetnz.org/topics/giant-celltumour-of-tendon-sheath-pathology

\section{Discussion}

There have been previous case studies reporting a localized tenosynovial giant cell tumor surrounding the Hoffa fat pad but never after an ACL reconstruction [1,4]. The initial lesion for our patient was read as a cyclops lesion on MRI but there can be subtle differences noted. MRI for a TSGCT shows a wellcircumscribed heterogeneous lesion on both T1 and T2 MRI due to the hemosiderin pigment content in the lesion [5]. A tenosynovial giant cell tumor is a rare intraarticular lesion that requires a high suspicion for clinical diagnosis. Management is currently centered around arthroscopic versus open removal of the lesion with serial monitoring and advanced imaging for recurrence [5].

The causes of TSGCT may include benign neoplastic process or reaction to an unknown stimulus versus response to repeated episodes of trauma or hemarthrosis [6]. In localized forms of TSGCT, the recurrence rate in both open and arthroscopic excision of these lesions in the knee is 7.1\% [7]. There is currently insufficient evidence to support open versus arthroscopic removal of the lesion. Open synovectomy entails a greater risk of knee stiffness and longer hospital stay and rehabilitation [8-9]. Arthroscopy, on the other hand, only enables partial resection, with an elevated risk of recurrence [10]. There are certain measures, such as limiting portal sites, excising the portal site tracts, and excising the lesion with the shaver one high suction, which may help reduce the rate of recurrence.

There have not been formal randomized studies comparing open surgery versus arthroscopic surgery. Radiation therapy has been used as an adjunct treatment to surgery particularly in cases of incomplete resection of tumor [11]. There have been limited studies as to the long-term consequences of intraarticular radiation and the possibility of radiation-induced sarcoma [12]. The Food and Drug Administration (FDA) approved a CSF-1 inhibitor, pexidartinib, for the treatment of adult patients with TSGCT. Investigational therapies include modulation of the CSF1R receptors, which addresses the underlying problem of the overexpression of CSF1 [13].

\section{Conclusions}

Overall, a localized tenosynovial giant cell tumor is a rare intraarticular lesion that requires a high suspicion for clinical diagnosis. Management is currently centered around arthroscopic versus open removal of the lesion with serial monitoring and advanced imaging for recurrence. The Diagnosis of this lesion in such an uncharacteristic location requires critical evaluation of advanced imaging as well as a pathologist available to evaluate the specimen. This unusual case in a young patient will also require routine evaluation for potential recurrence. The patient was followed at two weeks, six weeks, and three months postoperative as part of the routine ACL postoperative protocol. We plan to MRI the knee again at six months postoperative 


\section{Additional Information \\ Disclosures}

Human subjects: Consent was obtained or waived by all participants in this study. West Virginia University, Office of Research Integrity and Compliance issued approval N/A. Conflicts of interest: In compliance with the ICMJE uniform disclosure form, all authors declare the following: Payment/services info: All authors have declared that no financial support was received from any organization for the submitted work. Financial relationships: All authors have declared that they have no financial relationships at present or within the previous three years with any organizations that might have an interest in the submitted work. Other relationships: All authors have declared that there are no other relationships or activities that could appear to have influenced the submitted work.

\section{References}

1. Abdalla RJ, Cohen M, Nóbrega J, Forgas A: Synovial giant cell tumor of the knee. Rev Bras Ortop. 2009, 44:437-40. 10.1016/S2255-4971(15)30276-7

2. Nagase M, Araki A, Ishikawa N, et al.: Tenosynovial giant cell tumor, localized type with extensive chondroid metaplasia: a case report with immunohistochemical and molecular genetic analysis. Int J Surg Pathol. 2020, 28:447-53. 10.1177/1066896919889672

3. Kim SJ, Shin SJ, Choi NH, Choo ET: Arthroscopic treatment for localized pigmented villonodular synovitis of the knee. Clin Orthop Relat Res. 2000, 379:224-30. 10.1097/00003086-200010000-00026

4. Beytemür O, Albay C, Tetikkurt US, Oncü M, Baran MA, Cağlar S, Güleç MA: Localized giant cell tenosynovial tumor seen in the knee joint. Case Rep Orthop. 2014, 2014:840243. 10.1155/2014/840243

5. Jobe CM, Raza A, Zuckerman L: Pigmented villonodular synovitis: extrasynovial recurrence. Arthroscopy. 2011, 27:1449-51. 10.1016/j.arthro.2011.06.023

6. Ogilvie-Harris DJ, McLean J, Zarnett ME: Pigmented villonodular synovitis of the knee. The results of total arthroscopic synovectomy, partial arthroscopic synovectomy, and arthroscopic local excision. J Bone Joint Surg Am. 1992, 74:119-23. 10.2106/00004623-199274010-00015

7. Mollon B, Lee A, Busse JW, Griffin AM, Ferguson PC, Wunder JS, Theodoropoulos J: The effect of surgical synovectomy and radiotherapy on the rate of recurrence of pigmented villonodular synovitis of the knee. An individual patient meta-analysis. Bone Joint J. 2015, 97-B:550-7. 10.1302/0301-620X.97B4.34907

8. Gu HF, Zhang SJ, Zhao C, Chen Y, Bi Q: A comparison of open and arthroscopic surgery for treatment of diffuse pigmented villonodular synovitis of the knee. Knee Surg Sports Traumatol Arthrosc. 2014, 22:2830-6. 10.1007/s00167-014-2852-5

9. Ogilvie-Harris DJ, McLean J, Zarnett ME: Pigmented villonodular synovitis of the knee. The results of total arthroscopic synovectomy, partial, arthroscopic synovectomy, and arthroscopic local excision. J Bone Joint Surg Am. 1992, 74:119-23.

10. Sharma V, Cheng EY: Outcomes after excision of pigmented villonodular synovitis of the knee . Clin Orthop Relat Res. 2009, 467:2852-8. 10.1007/s11999-009-0922-7

11. Chandra AA, Agarwal S, Donahue A, Handorf E, Abraham JA: Arthroscopic versus open management of diffuse-type tenosynovial giant cell tumor of the knee: a meta-analysis of retrospective cohort studies. J Am Acad Orthop Surg Glob Res Rev. 2021, 4:e21.00217. 10.5435/JAAOSGlobal-D-21-00217

12. Griffin AM, Ferguson PC, Catton CN, et al.: Long-term outcome of the treatment of high-risk tenosynovial giant cell tumor/pigmented villonodular synovitis with radiotherapy and surgery. Cancer. 2012, 118:4901-9. 10.1002/cncr.26529

13. Benner B, Good L, Quiroga D, et al.: Pexidartinib, a novel small molecule CSF-1R inhibitor in use for tenosynovial giant cell tumor: a systematic review of pre-clinical and clinical development. Drug Des Devel Ther. 2020, 14:1693-704. 10.2147/DDDT.S253232 